\title{
Narrativas sobre a Universidade Federal de Goiás em Catalão 1986-2002 ${ }^{1}$
}

\author{
Wolney Honório Filho ${ }^{2}$ \\ Ana Paula Dias Pires ${ }^{3}$
}

\section{Resumo}

A criação de novas universidades no Brasil é um tema pouco estudado na história da educação brasileira. E uma lacuna que se abre nesse campo do conhecimento é quem são essas universidades. O objetivo deste texto é historicizar a UFG/CAC, a partir da seguinte questão: como a UFG/CAC é tratada nas narrativas constituídas tanto pelas atas de reuniões, quanto pelos professores que atuaram na instituição, no período de 1986 a 2002 ? A metodologia utilizada foi a pesquisa com fontes escritas, atas de reuniões, e fontes orais, entrevistas com professores da UFG/CAC. Como resultados, percebemos que a busca pela autonomia universitária é uma luta histórica da UFG em Catalão, traduzida em ações em prol da dedicação exclusiva, licença para a pós-graduação etc. Palavras-chave: Narrativa; Universidade; Goiás.

\section{Narratives about the federal university of Goiás in Catalão 1986-2002}

\section{Abstract}

The creation of new universities in Brazil is a topic that has been little studied in the history of Brazilian education. And a gap that opens up in this field of knowledge is who these universities are. The objective of this text is to historicize UFG / CAC, from the following question: how is UFG / CAC treated in the narratives made up of both the minutes of meetings and the professors who worked at the institution, from 1986 to 2002? The methodology used was the research with written sources, minutes of meetings, and oral sources, interviews with professors from UFG/ CAC. As a result, we realized that the search for university autonomy is a historic struggle by UFG in Catalão, translated into actions in favor of exclusive dedication, license for graduate studies etc.

Keywords: Narrative; University; Goiás.

\section{Introdução}

A Lei 13.634, de 20 de março de 2018, publicada no Diário Oficial da União em 21/03/2018 (BRASIL, 2018) traz o texto que cria a Universidade Federal de Catalão - UFCAT, a partir do desmembramento da Universidade Federal de Goiás - UFG. A nova universidade, em processo de transição em 2020, já nasce com 35 anos de experiência no ensino, pesquisa e extensão, com cerca de 4.000 alunos, pouco mais de 450 servidores efetivos, 130 servidores terceirizados, além

\footnotetext{
${ }^{1}$ Texto originário de pesquisa financiada pelo Programa de Iniciação Científica - CNPq

2 Universidade Federal de Catalão. Catalão - GO. whonoriof@gmail.com

${ }^{3}$ Universidade Federal de Catalão. Catalão-GO. anapaula.dpires@gmail.com
} 
de 29 cursos de graduação, onze mestrados e três doutorados ${ }^{4}$. A universidade tutora da UFCAT será a UFG.

A atual UFCAT nasce, portanto, da presença da UFG na cidade de Catalão - GO, interior do Estado de Goiás, em 1983, para atender a demanda de projetos de extensão universitária oriundos de Goiânia5 ${ }^{5}$ A partir de 1986, a Universidade de Goiás - Campus Avançado de Catalão (UFG/CAC) começa a se consolidar com os cursos de graduação de Letras e Geografia. Esse movimento só foi possível em função do investimento financeiro da Prefeitura de Catalão, que, por meio de convênios, arcava com as despesas financeiras de pagamento de pessoal, especialmente professores, e a UFG possuía, como responsabilidade, a coordenação dos processos seletivos de professores e da parte pedagógica. Quando, em 1996, foi implementado o curso de Ciências da Computação, já existiam, para além de Letras e Geografia, os cursos de Pedagogia, Matemática, Educação Física e História (SILVA, 2009).

Portanto, a UFG/CAC surge a partir de programas de interiorização e expansão do ensino superior, havendo assim a descentralização da oferta de vagas e a criação de instituições de ensino superior nas cidades do interior de Goiás. Inicialmente, a proposta da interiorização não era a de que os Campi Avançados fossem permanentes. Ao contrário, pretendia-se que eles funcionassem apenas para atender a demanda local ou regional. As criações de vestibulares minaram as possibilidades de cursos transitórios e temporários. Essa consolidação da UFG/CAC só foi possível graças aos convênios celebrados pela Prefeitura Municipal de Catalão e a UFG.

O objetivo deste texto é historicizar a UFG/CAC, a partir da seguinte questão: como a UFG/CAC é tratada nas narrativas constituídas tanto pelas atas de reuniões de seus conselhos, quanto pelos professores que atuaram na instituição, no período de 1986 a 2002? Este recorte temporal visa tomar o espaço de tempo de sua fundação (1986) até o ano de início do processo de concursos públicos federais (2002). Utilizamo-nos de duas fontes documentais: atas de reuniões da Congregação e dos Conselhos Pleno e Diretor no período de 1986 a 2002, bem como cinco entrevistas com professores que atuaram na instituição nesse período.

\footnotetext{
${ }^{4}$ Estas informações foram colhidas no site da UFCAT. Disponível em: https://catalao.ufg.br/. Acesso em: 28 fev. 2020. ${ }^{5}$ A UFG em Catalão teve várias nomenclaturas: Campus Avançado de Catalão; Campus Catalão; Regional Catalão, esta última ainda vigente no processo de transição. Para este artigo vamos adotar a sigla UFG/CAC, reconhecendo todo o processo histórico, no qual resulta a criação da UFCAT.
}

Periódico Horizontes - USF - Itatiba, SP - Brasil - e021006 


\section{A UFG/CAC - antecedentes}

Em 1985, um ano antes do início dos dois primeiros cursos, Geografia e Letras, foi aprovado, pelo egrégio conselho universitário da UFG, o Regimento do UFG/CAC (UFG/RC, 1985, s/p). No Título II deste Regimento, Da Estrutura e Administração, diz-se que a Direção e Administração será exercida pelos seguintes órgãos: 1) Departamentos; 2) Conselho Departamental; 3) Congregação; 4) Diretoria. Percebe-se aqui que a Reitoria da UFG, na época, criou uma estrutura mínima de gestão, com diretoria, congregação e departamentos. Uma estrutura, diga-se de passagem, minimamente semelhante à estrutura da universidade em Goiânia.

No entanto, em 1992, a partir da organização de professores, alunos e técnicos administrativos da UFG/CAC, a Congregação dos Docentes, que na proposta de Regimento Interno se diz Campus Catalão, aprova o primeiro Regimento Interno do Campus (UFG/RC, 1992a), na época, não foi reconhecido pela Reitoria da UFG. Neste Regimento, estabelece-se a seguinte estrutura pedagógica: 1) Congregação de Docentes; 2) Conselho Pleno; 3) Coordenação de Pós-Graduação, Pesquisa e Extensão; 4) Coordenação de Graduação; 5) Coordenadores dos Cursos de Graduação; 6) Corpo Docente; 7) Corpo Discente. Apesar deste Regimento Interno não receber aprovação da Reitoria da UFG, é necessário ressaltar que a busca pela autonomia passava "necessariamente pela aprovação do nosso Regimento pelos organismos da Universidade" (UFG/RC, 1992a, s/p).

Este primeiro Regimento Interno elege o Conselho Pleno como um órgão colegiado representativo constituído por a) O Diretor do Campus de Catalão; b) O coordenador de Graduação; c) O Coordenador de Pós-Graduação, Pesquisa e Extensão; d) 1 representante dos coordenadores de cursos; e) 2 representantes do corpo docente; f) 1 representante do corpo discente. Além disso, compete ao Conselho Pleno discutir, aprovar e otimizar políticas, propostas e atividades didático-pedagógicas (UFG/RC, 1992a).

Em seis anos de existência (1986-1992), com seis cursos de licenciatura, a UFG/CAC, pelas mãos de seus docentes, técnicos administrativos e alunos, desenha uma estrutura para si de uma pequena universidade no interior de Goiás sem a aprovação legal da Reitoria da UFG. Constatase, portanto, uma ebulição de uma universidade no interior, não só do País, do Estado de Goiás, 
mas da própria Universidade Federal de Goiás, que projetou sua interiorização a partir da realidade universitária da capital, mas que viu emergir uma força resistente à submissão institucional.

\section{A pesquisa}

Bolívar (2014, p.330) nos diz que "O enfoque biográfico e narrativo da organização oferece um modo alternativo para descobrir, analisar e teorizar os processos e práticas educativas na escola" 6 . Ao compreendermos as instituições escolares como construídas socialmente por conjuntos de relatos vividos e transmitidos, evocamos "as narrativas, como nós estratégicos na construção de sentido comunitário, são os meios que se manifesta a memória institucional, a história e se constitui a identidade organizacional e profissional" (BOLÍVAR, 2014, p.330 $)^{7}$.

A UFG/CAC é vista, aqui, como uma construção narrativa na medida em que "as histórias e os relatos da organização contribuem para mediar, compartilhar e, em último extremo, construir a realidade organizativa" (BOLÍVAR, 2014, p.330) ${ }^{8}$. Mas o que de fato estamos chamando de relatos/narrativas?

Compreendemos as atas, para além de meros documentos formais, como narrativas institucionais e como fontes de memória em educação. As "atas também podem servir como uma rica fonte documental, sobremaneira para a história da educação. Dentro desta perspectiva, a ata é entendida como um lugar de memória" (NORA, 1993 apud ESQUINSANI, 2007, p.104). Em outras palavras, este documento compõe as nuances históricas da conjuntura que estamos trabalhando, são formas de dar sentido à realidade, "à experiência passada e aos acontecimentos atuais" (BOLÍVAR, 2014, p.339) ${ }^{9}$.

Essas atas foram encontradas no Centro de Informação, Documentação e Arquivos

\footnotetext{
${ }^{6}$ El enfoque biográfico y narrativo de la organización ofrece um modo alternativo para describir, analizar y teorizar los processos y prácticas educativas en la escuela.

${ }^{7}$ Las narrativas, como nudos estratégicos em la construcción del sentido comunitario, son los medios por los que se manifiesta la memoria institucional, la historia y se constituye la identidad organizacional y profissional.

${ }^{8}$ Las historias y relatos de la organización contribuyen a mediar, compartir y, en último extremos, constituir la realidad organizativa.

${ }^{9}$ A la experiencia pasada y a los acontecimientos actuales.
} 
(CIDARQ), da UFG/CAC, órgão criado em 2007 sob a égide da Lei 8.159/91 e se constitui como "ponto central no processo de revitalização, recuperação documental e de acesso à informação: memórias, ou lugar de memórias, que constituem a história sócio-política dos processos, das lutas, interesses e trajetórias que marcam a UFG Catalão desde sua fundação" (HONÓRIO FILHO; PIRES, 2019, p.17).

Para fins metodológicos da pesquisa, foram selecionadas para análise cinco caixas de documentos sob a guarda do CIDARQ: caixa 2, 11, 12, 13 e 47. As temáticas que envolviam os documentos da caixa 2 estavam estritamente relacionadas aos livros de registro de atas da Congregação e do Conselho Pleno de 1993. A caixa 11, abrange os livros de registro de atas da Congregação, de 1990 a 1992 e do Conselho Pleno, de 1992 a 1997. A caixa 12 dispõe de atas das eleições do CAC, de 1999, para os cargos de Vice-Diretor, Coordenador de Pós-Graduação e Pesquisa, assim como representantes para compor junto ao Conselho Diretor, tanto do corpo docente, quanto do corpo discente. Além disso, esta caixa contém fontes documentais referentes ao convênio que celebra o acordo (e tensão) político-administrativo entre Prefeitura de Catalão e UFG de 1994, 1995 e 1996, bem como Relatórios de Gestão. Por fim, a caixa 47 dispõe de documentos circulares emitidos pela Administração e protocolos para eleições do Conselho Diretor 2002.

Um outro mecanismo utilizado para delimitar os caminhos de nossa pesquisa é a produção de uma "ficha de leitura" que nos auxiliaram na investigação das atas. É uma tentativa de sistematização daquilo que há na ata, nos servindo para a produção de dados.

Quadro 1 - Ficha de leitura

\begin{tabular}{|c|c|}
\hline DATA & \\
\hline PAUTA & \\
\hline CUMPRIMENTO DE PAUTA & \\
\hline MEMBROS & \\
\hline COMO A ATA DESCREVE A UFG/CAC & \\
\hline RASURAS/MODIFICAÇÕES & \\
\hline
\end{tabular}

Fonte: Ficha de Leitura das Atas construída pelos autores. 
Outra produção de dados foram cinco entrevistas que encontramos no acervo do NEPEDUCA ${ }^{10}$, realizadas em 2017 com professores que trabalharam na UFG - Catalão, no período proposto por esta pesquisa. As entrevistas utilizadas foram com Elza Maria Staciarini; Maria José da Silva; Marcio Roberto Rocha Ribeiro; Ullysses Rocha Filho e Idelvone Mendes Ferreira ${ }^{11 .}$

Le Goff (1996) afirma que nos dias atuais, a história é o que transforma os documentos em monumentos (p.546, grifos do autor). Documento como um produto da sociedade que o fabricou, como algo que fica, que dura e que traz um testemunho, que deve ser analisado pelo pesquisador. E, monumento, como roupagem, "uma aparência enganadora, uma montagem" (LE GOFF, 1996, p.548). Para este autor, é a análise do documento como monumento, ou seja, o questionar do documento, que confere um caráter científico ao trabalho do historiador. No nosso caso, os documentos serão as narrativas colhidas nas entrevistas e as narrativas advindas das atas dos conselhos.

\section{Os documentos como narrativas}

Tomamos tanto as atas quanto as entrevistas como narrativas. Passeggi (2014, p.227) nos diz que "quer a narração seja construída pelo homem comum, quer pelo historiador, o romancista, o erudito, o teólogo, o cientista, ela é sócio-histórica, situada e traz as marcas da subjetividade, pondo em relação suas coordenadas espaço-temporais a partir do aqui e agora". Ainda sob esta ótica

As narrativas tornam-se, ao mesmo tempo, um parâmetro linguístico, psicológico, cultural e filosófico fundamental para explicar a natureza e as condições da existência humana (ibidem), constituindo-se entradas potencialmente legítimas para se ter acesso aos modos como o sujeito (ou uma comunidade) dá sentido à sua experiência, organiza suas memórias, justifica suas ações, silencia outras. Nesse sentido, elas oferecem padrões de interpretação, que contribuirão, tanto para o conhecimento do humano, quanto para o próprio aprimoramento da pesquisa qualitativa interpretativa (PASSEGGI; SOUZA; VICENTINI, 2011, p.9).

\footnotetext{
${ }^{10}$ NEPEDUCA - Núcleo de estudos e pesquisa em educação. Sala 203, prédio L, Universidade Federal de Goiás - Regional Catalão.

11 Todos os entrevistados assinaram o Termo de Consentimento Livre - TCLE. Projeto aprovado pela CAAE/UFG 60989816.3.0000.5083. Parecer 1.997.188
}

Periódico Horizontes - USF - Itatiba, SP - Brasil - e021006 
Corroborando com Bolívar (2014), compreendemos a narrativa como um espaço privilegiado na construção de uma memória institucional e de versões outras desta história. Assim, para o autor, as narrativas, as memórias e representações que se constituem entremeadas a elas fornecem meios para a reflexão das mais variadas versões que daí podem ser elaboradas.

Sua reconstrução biográfico-narrativo pode ter a virtualidade de coletar o conhecimento adquirido, dinamizar e questionar o que é feito dentro do desenvolvimento institucional... Temos ressaltado o valor da história institucional, como reconstrução do passado, para desenhar - devidamente situado - o horizonte do desenvolvimento futuro (BOLÍVAR, 2014, p.332) ${ }^{12}$.

Ao propor esta investigação, a partir das atas e entrevistas, passamos a considerá-las como produções biográfico-narrativas em educação, um testemunho. Os sujeitos da educação, que trabalharam na condição de docentes, ou compuseram historicamente a Congregação e/ou o Conselho Pleno da UFG/CAC, são escritores e leitores de suas próprias vidas, relacionadas à vida institucional. Ao relatarem, discutirem, debaterem e deliberarem sobre temas da universidade, os sujeitos produzem narrativas que dão sentido às suas experiências de vida, à experiência humana (BOLÍVAR; DOMINGO; FERNÁNDEZ, 2001), e, acrescentamos, à experiência institucional. As pessoas vivem suas histórias e as de outras pessoas. Clandinin e Connelly (2011) consideram que a narrativa é o melhor modo de representar e entender a experiência. A história das instituições se entrecruza reciprocamente às histórias de seus atores. Ao narrar, seja de forma oral ou escrita, para além dos sujeitos reviverem esta história, delimitam suas relações com o meio. Assim, no caso desta pesquisa, tomamos as entrevistas e atas de reuniões do Conselho Pleno como narrativas que carregam em si expressões sócio históricas. São versões de atores imersos no cotidiano concreto da instituição escolar.

Para Esquinsani (2007, p.104), "as atas elaboradas para/em/a partir de reuniões, podem ser qualificadas enquanto registros formais de um encontro promovido por um órgão, associação, entidade ou grupo de sujeitos [...] visando deliberar sobre assuntos de interesse comum ou repassar informações".

\footnotetext{
12 Su reconstrucción biográfico-narrativa puede tener la virtualidade de recoger el saber adquirido, dinamizar y cuestionar lo que se hace, dentro del desarrollo institucional... Hemos ressaltado el valor dela historia institucional, como reconstrucción del passado, para disñar - debidamente situado - el horizonte de desarrollo futuro.
} 
As atas são encaradas como documentos que possuem como função de reproduzir fielmente aquilo que se passa nas reuniões, suas deliberações, decisões e discussões. No entanto, para nós as atas ganham importância sobremaneira como uma fonte documental fundamental para a história da educação, isto é, como um lugar privilegiado de memória (NORA, 1993 apud ESQUINSANI, 2007).

Compreendemos o documento a partir de noções ampliadas do mesmo. Isso significa que todo vestígio que diz do que chamamos de passado, tudo aquilo que serve de testemunho é considerado documento ou fonte (CELLARD, 2012). Porém, o documento escrito "constitui um instrumento que o pesquisador não domina. Embora tagarela, o documento permanece surdo, e o pesquisador não pode dele exigir precisões suplementares" (CELLARD, 2012, p.295-296). Isso se mostra imperativo em nossa pesquisa no CIDARQ. Os documentos escritos e arquivados apresentam-se de forma limitada, geralmente, quando tomamos uma ata, há a indicação de um fato, mas não há a descrição do mesmo. Outra questão é que as atas não tinham uma estrutura formal como as que encontramos nas reuniões ordinárias da universidade, atualmente. Isso nos diz que a narrativa era praticamente livre, não havendo marcação de linhas, raras algumas exceções. As pautas das reuniões não eram discriminadas. Nem todas possuem a assinatura dos presentes nas reuniões e, quando possuem, são rubricas ilegíveis. Outro detalhe que nos chama a atenção é que a autoria das atas não estava submetida a uma pessoa em específico no cargo de secretária. São autores variados, o que nos leva a pensar que era feito um revezamento na composição da ata, conforme as pessoas presentes nas reuniões.

\section{As dimensões da UFG/CAC sob o ponto de vista das narrativas}

Para Bolívar, Domingo e Fernández (2001), há três posturas de análise: uma primeira é a ilustrativa, na qual a narrativa serve para ilustrar o argumento do pesquisador. Outra, a hiper empirista, a qual o pesquisador reduz ao mínimo os comentários, deixando as narrativas falarem por si. E, uma terceira, a postura analítica, que busca produzir sentido de modo metódico. Esta reconstrução de sentido, porém, se ancora numa análise de linguagem um tanto quanto formalista, conforme o autor, o que pode fragmentar e descontextualizar as narrativas dos sujeitos. Assim, uma fidelidade extrema ao discurso narrativo limita a análise. 
Por outro lado, análises muito formais podem expropriar o narrador de suas próprias representações de mundo.

O autor, então, propõe fazer uma genealogia do contexto: “A tarefa é, por um lado, decifrar significativamente os componentes e dimensões relevantes das vidas dos sujeitos, e por outro - situar os relatos narrativos em um contexto que contribua para criar um quadro que tenha um sentido mais amplo" (BOLÍVAR; DOMINGO; FERNÁNDEZ, 2001, p.201) ${ }^{13}$. Esta seria uma análise que não se limitaria às narrativas, transcrevendo-as apenas, nem prescindiria das mesmas. Marcadamente com enfoque indutivo, busca teorizar através dos testemunhos recolhidos. Não se trata, portanto, de representar as vozes dos sujeitos. Mas, produzir, do ponto de vista da pesquisa, outra narrativa. Outra narrativa frente a "relatos biográficos que constroem humanamente (sentir, pensar, atuar) uma realidade" (BOLÍVAR, DOMINGO E FERNÁNDEZ, 2001, p.205) $)^{14}$

Ao entendermos as narrativas enquanto, na expressão de Bolívar, Domingo e Fernández (2001), "formas de construir sentidos", compreendemos a instituição escolar como uma realidade social e historicamente construída "que - por isso mesmo - tem gerado estruturas, funções, padrões de ações, significados, rituais, etc.; ou seja, uma cultura organizativa" (BOLÍVAR, 2014, p.332) ${ }^{15}$. Assim, o que nos interessa é tomar essa construção social de uma instituição - a UFG/CAC -, por meio de narrativas em entrevistas e atas que os professores dos conselhos escreviam, confirmando o ocorrido nas reuniões, ou seja, aquilo que experimentaram na condição de trabalhadores da universidade e ocupantes dos conselhos e que relatam essas experiências, aprovadas em atas dos conselhos.

Nesse sentido, para além de um enfoque conceitual, a narrativa se configura enquanto método de investigação e interpretação (BOLÍVAR; DOMINGO; FERNÁNDEZ, 2001). A leitura da realidade - no sentido de interpretar - à luz das narrativas produzidas pelos atores sociais se convertem em uma perspectiva própria de investigação.

\footnotetext{
${ }^{13}$ La rara es, por uma parte, descifrar significativamente los componentes y dimensiones relevantes de las vidas de los sujetos, y- por outra - situar los relatos narrativos em um contexto que contribuya a proveer uma estrutura em que tome um sentido más amplio

${ }^{14}$ Relatos biográficos que construyen humanamente (sentir, pensar, actuar) uma realidad.

${ }^{15}$ Que - por eso mismo - ha generado estructuras, roles, patrones de acción, significados, rituales, etc.; es decir, su cultura organizativa.
}

Periódico Horizontes - USF - Itatiba, SP - Brasil - e021006 
Para dar encaminhamento à análise e interpretação das fontes documentais produzidas nesta pesquisa, utilizamos a concepção de Bardin (2011), com o "objetivo de fornecer uma representação dos dados" (p.119). Para isso, elegemos algumas categorias, conforme o quadro abaixo:

Quadro 1: Fontes documentais

\begin{tabular}{|c|c|}
\hline ATAS & ENTREVISTAS \\
\hline Dedicação Exclusiva & A escolarização dos docentes; \\
\hline Licenças Remuneradas & Trabalho - atuação na universidade; \\
\hline Eleições & Visão da universidade; \\
\hline Regimento Interno & as transformações da universidade; \\
\hline & a percepção dos entrevistados diante do \\
trabalho realizado.
\end{tabular}

Fonte: Os autores.

\section{O que nos dizem as entrevistas?}

Nas narrativas dos docentes verifica-se a marca hegemônica da Escola Pública na escolarização dos mesmos. Talvez seja uma tendência, qual seja, a de que docentes do ensino superior, que se especializam na área das humanas, têm, em sua maioria, origem escolar na Escola Pública, tendo em vista especialmente o ensino fundamental e médio.

O trabalho na universidade se diferencia entre o Ensino, a Pesquisa, a Extensão e a Administração. Este lugar que o docente ocupa, entre essas quatro instâncias de atuação, ou uma combinação entre elas, por exemplo, atuar no ensino e pesquisa, ensino e extensão, ou ainda na coordenação ou chefia de algum órgão, possibilita ao mesmo um olhar sobre a universidade pautado neste lugar profissional. Quando a atividade se restringe à sala de aula, cumprindo as obrigações da pesquisa e extensão, que é estimulada pela UFG, e não ocupa cargos administrativo, percebe-se que o docente tem uma visão mais utópica, do que aqueles que coordenaram cursos, ou mesmo dirigiram a UFG/CAC, como é o caso da professora Elza.

Outro item diferenciador é entre os professores que iniciaram suas atividades profissionais no início dos anos de 1990, atuando e construindo a universidade, e aqueles que chegaram no final da década de 1990. Professores como Idelvone, Elza e Maria José, ao 
ingressarem na UFG/CAC, adotaram a luta de que a UFG/CAC deveria ser mais do que aquilo que existia no final dos anos 1980. Não vamos afirmar que Márcio e Ulysses, que ingressaram no Campus em 1999 e 1994, respectivamente, não tinham isso em mente. O fato é que o clima universitário no início de 1990 parecia estar mais acalorado, em função também da utopia de uma universidade interiorizada e diferente das demais, geralmente situadas nas capitais dos Estados.

Nas entrevistas, percebe-se que ao ingressarem na UFG/CAC, os professores não pensavam trabalhar ali por muito tempo. O que encontraram de infraestrutura os assustou. Elza narra que veio para ficar pouco tempo, era o tempo de estruturar a Universidade como campo de estágio e depois retornaria para Goiânia. Maria José não acreditava que o espaço da UFG/CAC era onde é hoje, quando fez a primeira visita. Márcio ao chegar à UFG/CAC é perguntado "O que você veio fazer neste fim de mundo?".

Todos tiveram o apoio e orientação de colegas, já professores, para seguirem a carreira de professor como alternativa, ainda que somente Elza pensava neste caminho anterior à sua graduação em Geografia. Idelvone teve seu concurso orientado por um professor amigo para que viesse para Catalão. Ullysses pensava em ingressar no Direito e por orientação de duas professoras segue para a carreira acadêmica. Ou seja, a ida para trabalhar na Universidade está associada às relações com ex-professores, colegas de universidade, que os indicam ou convidam a fazer os concursos públicos.

A atuação dos mesmos é divergente quanto à participação política e a maneira de pensar a Universidade. Elza, ao ingressar na UFG/CAC, antes da criação dos primeiros cursos, Letras e Geografia, o faz atuando na administração, organização e estruturação para que cursos de Goiânia pudessem ser contemplados em Catalão, ofertando aos alunos estágios dos cursos da área da saúde. Depois, quando retorna para coordenar o curso de Geografia, ou dirigir a UFG/CAC, também o faz com a mesma perspectiva política, qual seja, a de que a graduação em Catalão deveria ter a mesma qualidade da sede da UFG, em Goiânia.

Maria José, assim como Idelvone e Elza, mesmo com diferentes recortes, apresenta uma visão militante sobre a universidade. Ulysses, por exemplo, que foi, inicialmente, aluno da Letras e, depois, ingressa como professor mostra uma perspectiva, em sua entrevista, mais forte como aluno do que como docente da UFG em Catalão. De todo modo, as histórias de vida dos 
entrevistados nos indicam, pelas marcas de quem foram os melhores professores para eles, as preferências de estudos, disciplinas, leituras, que a atuação profissional, a docência na universidade, não tem a princípio uma origem determinada. Há elementos que nos indicam semelhança, como a frequência em Escola Pública. Mas, entendemos que a sociabilidade construída na universidade, no momento da formação na graduação, levaram-lhes a ver a profissão como alternativa de trabalho.

Isso nos leva a pensar sobre a criação de uma Universidade, pautada pela escolha da profissão dos seus docentes. Ou mesmo, sobre a biografia institucional da UFG em Catalão, a partir do modo como seus docentes vão de encontro a ela e à profissão. Todos, a seus modos, são atuantes na profissão que escolheram e imergem, não apenas nas funções didático pedagógicas, mas em pensar uma Universidade em Catalão, para além dos seus cursos onde são lotados.

\section{$\mathrm{O}$ que nos dizem as atas?}

Nos termos do convenio celebrados pela Universidade e pelo município de Catalão, à prefeitura cabia os aspectos financeiros e orçamentários, o pagamento de professores, condescendência de dedicação exclusiva (DE) e licenças remuneradas. Assim, "os professores seriam contratados pela Prefeitura, apesar da UFG fazer a seleção pública" (SILVA, 2009) e, portanto, seriam vinculados juridicamente ao município e não a união. Havia, nesse sentido, uma diferenciação das carreiras docentes municipais e as federais. E, apesar da DE ser incluída nos convênios somente a partir de 1989, esta não foi concebida a todo quadro docente (SILVA, 2009). $\mathrm{Na}$ leitura das Atas, alguns aspectos da DE eram frequentemente abordados, formando-se comissões para a avaliação dos pedidos de DE. Esse é um ponto especialmente valioso em nossa pesquisa, na medida em que se considera os exercícios das atividades funcionais em tempo integral e se aprofunda o contato do docente com a realidade concreta e situações enfrentadas pela instituição.

As autorizações pela prefeitura de licenças remuneradas também são fatores para a nossa análise, visto que as atas as colocam em discussão com grande frequência. Ao compreendermos as licenças remuneradas como políticas de aprimoramento dos docentes, nos deparamos com a comunidade acadêmica do Campus Catalão (CAC) engajada com os compromissos para a criação 
de "condições físicas, didático-pedagógicas e políticas [que possibilitam] não somente a existência dos cursos" (SILVA, 2009, p.121) mas também condições reais de funcionamento. Nos parece que, as licenças remuneradas, assim como a dedicação exclusiva, colocam em xeque a identificação e o pertencimento às lutas da instituição.

Os meandros da trajetória da UFG/CAC são marcados por políticas estruturais, mas compreende também as práticas sociais de seus atores, a maneira como estes apropriam o território permeado de tensões que se configura a instituição naquele momento:

Em seguida a prof. Elza disse aos presentes sobre as dificuldades encaradas na apresentação do vestibular para Ciências da Computação em Catalão junto ao Conselho de Ensino e Pesquisa CEPEC em virtude do atraso por parte da Prefeitura no cumprimento do termo de compromisso firmado (UFG/RC, 1997a);

[Prof. Wolney] em seguida comunica aos presentes o projeto de especialização que o curso de pedagogia está elaborando [...] O prof. Laurindo solicita lâmpadas para substituir as que estão queimadas na sala de aula. $O$ prof. Madson diz que os quadros de giz estão precisando de reforma (UFG/RC, 1998);

Na sequência informa as atividades já realizadas no âmbito do PROEXT, inclusive o projeto de laboratório de ciências. Sobre este último disse que foram adquiridos os microscópios e balanças e alguns reagente (UFG/RC, 1997b);

O coordenador do curso de Pedagogia defende a criação e construção de uma biblioteca de intercâmbio de pesquisa (UFG/RC, 1997b).

A apropriação desse espaço político e politizador que é a UFG/CAC também se evidenciam em outros documentos pesquisados além das atas, como, por exemplo, o texto Campus de Catalão: uma universidade? (UFG/RC, 2000b, s/p).

Eu pessoalmente acredito que a luta por novos cursos é fundamental para a criação de uma futura universidade (fundação neste campus). Entretanto, alguns cursos já contam com salas de no máximo três mesas (significa três professores na sala), enquanto outros enfrentam sérios problemas para abrigar seus docentes. Para mim deveria ser prioridade para 2001 buscar recursos para construir salas de professores, salas para as coordenações, todas informatizadas, bem como salas de vídeo e atendimento de alunos, núcleo de estudos, para cada curso (o que poderíamos chamar de laboratório de ensino). [...] é preciso não esquecer a importância que uma nova biblioteca terá para este Campus. Em se confirmando que esteja previsto uma biblioteca para o CAC, 
com recurso do orçamento do Estado de Goiás, a Direção terá um papel fundamental em estar acelerando, junto aos deputados e governador, a construção da mesma.

Assim, embora o contexto em que estes atores estão inseridos seja, inevitavelmente, atravessado por tensões e conflitos, seja com a Universidade em Goiânia, seja com a Prefeitura, eles são constitutivos da consolidação dos cursos em Catalão, e nos termos de Silva (2009, p.123) "havia vozes no campus que estavam impregnadas pelo espírito da Universidade".

Os atores que compõem a história do CAC estavam entremeados à luta para a inserção da instituição nas instâncias acadêmico-científico e políticas da Universidade. Nesse sentido, o destaque das eleições para os cargos de gestão pedagógica são elementos centrais nas discussões encontrada nas atas do Conselho e em outros documentos. Em uma circular de 03 de maio de 1989 (UFG/RC, 1989, s/p) "Os coordenadores [dos cursos] pediram que os serviços de secretaria sejam autônomos, diminuindo a burocracia e não tendo que passar todos os processos pelo crivo de Goiânia". Vale destacar que, tanto o processo esboçado acima que permeia as práticas sociais de seus atores, a maneira como estes apropriam, engajam e se comprometem frente às lutas e tensões que os atravessam, quanto as eleições para cargos de gestão pedagógicas, na tentativa de que estes sejam desvinculados diretamente da Reitoria, nos apontam para a busca por autonomia. O que nos coloca a pergunta o que seria, na visão desses atores, a autonomia da UFG/CAC?

Na tentativa de compreender essa pergunta, é necessário voltarmos à construção do Regimento Interno da UFG/CAC. Entre os anos de 1988 e 1996 a UFG se engajou no processo de revisão e avaliação de seu Estatuto e Regimento Interno. A essa altura, a comunidade acadêmica da UFG/CAC entende a "necessidade de se buscar uma alternativa regimental que desse suporte ao funcionamento do campus. Nesses termos, uma proposta de Regimento Interno foi elaborada pelo CAC" (SILVA, 2009, p.134). Em diversos momentos em nossa pesquisa nos deparamos com a urgência demonstrada nas reuniões descritas nas atas em relação ao Regimento:

A prof. Marta lembrou da urgência de se formar uma comissão para a elaboração do projeto político pedagógico do CAC [...] O projeto seria pensado em todos os níveis. (UFG/RC, 1992b). 
A prof. Elza apresenta aos conselheiros os novos estatutos e Regimento da UFG e ressalta sobre a necessidade de atualização do Regimento do CAC (UFG/RC, 1997a).

A atualização do Regimento Interno da UFG/CAC apontava para a organização de outros debates, sendo eles vinculados ao fato da Coordenação de Curso ser da UFG/CAC e não de um professor da UFG/Goiânia e para a transformação do Campus em Unidade da Universidade Federal de Goiás (SILVA, 2009). E, acrescentamos, posteriormente um movimento para a federalização desta unidade. Seria, então, a elaboração do Regimento Interno um símbolo de autonomia do campus, no sentido expresso por seus atores, de não subordinação política e acadêmico-pedagógica às imposições da UFG/Goiânia ou mesmo pela Prefeitura de Catalão? Há evidências que sim, conforme o trecho do Relatório de Mandado de Vice-Diretor abaixo (UFG/RC, 2000a, s/p):

[...] gostaria de apontar apenas outro ponto: a ênfase na aprovação do regimento do CAC. A busca pela autonomia do CAC passa necessariamente pela aprovação do nosso Regimento pelos organismos da Universidade [...]. Do ponto de vista administrativo, é bom lembrar que estamos funcionando com um regimento que, apesar de ter sido reelaborado em 1998, foi pensando no início de 1992. Desde então, penso que há ainda certos equívocos. Não vejo ainda autonomia para os cargos de Coordenação de Graduação e PósGraduação. Várias das funções destes cargos ainda são resolvidos pela Direção do CAC [...]. É preciso que este conselho promova mais diálogos com a reitoria para que possa reconhecer oficialmente o que fazemos enquanto universidade.

No documento referente à Proposta de Regimento Interno do Campus, de 04 de dezembro de 1992 vemos que

Atualmente o Campus Avançado de Catalão tem os seus cursos subordinados pedagogicamente aos respectivos Departamentos da UFG, que indicam um Coordenador para os cursos ministrados neste Campus escolhido dentre os professores de seu quadro docente, sem qualquer consulta prévia aos docentes de Catalão [...]. A maioria destes coordenadores acumulam funções, o que dificulta sua atuação e o devido acompanhamento das atividades desenvolvidas neste Campus [...]. No sentido de agilizar o processo de autonomia dos cursos existentes em Catalão, promovendo a participação ativa de seu corpo docente, na constituição e efetivação de um projeto pedagógico próprio, propõe-se que o coordenador de curso pertença ao quadro docente do Campus de Catalão [...]. Para se alcançar a autonomia pedagógica almejada, propõe-se uma relação

Periódico Horizontes - USF - Itatiba, SP - Brasil - e021006 
direta entre a UNIDADE de Catalão e a Reitoria, como ocorre com as demais unidades de UFG (UFG/RC, 1992a, s/p).

Assim, compartilhamos com a ideia de Silva (2009, p.144) de que "a implementação dessa nova estrutura regimental da UFG/CAC comprova que as práticas sociais e políticas da comunidade acadêmica tendem a demarcar na UFG uma relação entremeada pelas disputas econômicas" e, acrescentamos, políticas. Isso se demonstra nas Atas do Conselho Pleno de 27 de junho e 14 de setembro de 1994, respectivamente, em que "O prof. Eguimar fala que o campus passa por um momento difícil, a política da prefeitura e da universidade não tem favorecido o desenvolvimento do campus" (UFG/RC, 1994a, s/p) e "[Eguimar] diz também que a Prefeitura e a Universidade pensam que no Campus não existe produção" (UFG/RC, 1994b, s/p). Naquele momento era necessário o reconhecimento por parte da Reitoria daquilo que UFG/CAC fazia enquanto universidade, apoiada no tripé Ensino, Pesquisa e Extensão.

Estas mudanças administrativas, acadêmico-pedagógicas, de produção e de carreira docente foram provenientes dos movimentos internos do CAC e de seus atores. Na medida em que se administrava, organizava e apropriava-se do espaço público, se construíam relações com atividades políticas e, simultaneamente politizadoras, na construção da autonomia da UFG/CAC.

\section{Considerações finais}

Vemos, pelos relatos dos docentes que trabalharam na UFG/CAC, inicialmente órgão suplementar e, depois, unidade regional da Universidade Federal de Goiás, que este campus é pautado por uma presença intercultural, ou seja, uma "pluralidade de pertenças", conforme nos diz Delory-Momberger (2009), traduzida pela diversidade de origens dos docentes e, porque não dizer, de alunos e técnicos administrativos. Pelas narrativas, a universidade é vista, naquele período de 1986 a 2002, tanto como precária, conforme nos diz Maria José da Silva, como um Santuário, na perspectiva de Ulysses.

O professor, com o seu trabalho, e a Instituição se constroem simultaneamente. A precariedade estimula a ação militante? Não temos dados para responder a isso. Porém, a distância entre uma visão de precariedade, mesmo que tenha sido relacionada à infraestrutura 
e um santuário, que é atribuída ao lugar de conhecimento, é grande. Certamente, nesse entremeio, existem as lutas cotidianas de cada um, seja em sala de aula, reuniões de curso, sindicato e conselhos.

Na UFG em Catalão, no início da década de 1990, apesar de pequena, em relação ao número de alunos, professores e técnicos administrativos, bem como de infraestrutura, sonhava-se grande. A utopia estava solta. Não existia apenas o fato de ser contratado por 40 horas e executar esta função, para os professores. Havia um ideal de construção de um patrimônio público autônomo.

Isso é perceptível também nas atas que pesquisamos. O tema das Eleições pode nos indicar o movimento interno da comunidade acadêmica em busca de autonomia, na medida em que era necessário que os cargos administrativos fossem ocupados pelos professores de Catalão, ao invés de nomes indicados pela Reitoria, na sede Goiânia. Urgia a necessidade de sujeitos que conheciam e vivenciavam em seu cotidiano as labutas da realidade concreta. Outrossim, mostrava-se fundamental a dedicação exclusiva, concedida pela Prefeitura, já que alguns professores possuíam outros vínculos empregatícios e se encontravam abarrotados de funções a serem exercidas. As licenças remuneradas compreendem políticas de valorização e incentivos à formação dos docentes. Por fim, o Regimento Interno, tal como as outras categorias, nos ajuda a entender os diálogos com a Reitoria para que se possa reconhecer a autonomia do Campus Catalão, isto é, os debates e práticas universitárias que eram engendrados na UFG/CAC.

Ao levarmos em consideração o debate sobre a federalização e implementação da UFCAT, pode se pensar que tal processo e as transformações estruturais e culturais são discussões novas. No entanto, como vimos, esse debate há muito já vinha sendo realizado. E mais, na medida em que os debates acerca da autônima da UFG/CAC eram realizados, a comunidade acadêmica materializava tais debates em suas gestões, em suas lutas, ora com a Reitoria ou com a Prefeitura de Catalão. Isso se mostra evidente na busca da UFG/CAC pelo seu Regimento Interno e por Eleições para os cargos administrativos, pela busca incessante por dedicação exclusiva e licenças remuneradas. Portanto, o debate que era realizado nas reuniões administrativas da UFG/CAC, isto é, debate que constitui sua narrativa institucional, demonstra uma prática universitária (ainda não reconhecida pela reitoria), mas que busca a autonomia, seja em relação a Reitoria, seja em relação a Prefeitura. Os dados, análises e interpretações desse processo sócio histórico 
nos permitem ampliar o horizonte do nosso olhar na importância da compreensão do presente à luz do passado.

Por fim, queremos destacar ainda que, frente a todo o processo de desmonte e sucateamento da Universidade Pública Brasileira que veem acontecendo, com mais intensidade, no decorrer dos últimos anos, as discussões aqui apresentadas são de extrema valia para pensarmos as lutas e trajetórias pela autonomia universitária que, infelizmente, tem sido colocada em descrédito no Governo Federal desde 2018.

\section{Referências}

BARDIN, L. Análise de conteúdo. Trad. Luís A. Reto e Augusto Pinheiro. São Paulo: Edições 70, 2011.

BOLÍVAR, A.; DOMINGO, J.; FERNÁNDEZ, M. La investigación biográfico-narrativa en educación: enfoque y metodología. Madrid: La Muralla, 2001.

BOLÍVAR, A. Narrar la organización educativa: memoria institucional y constitución de la identidade. In: BOLÍVAR, A. La investigacion (auto)biográfica en educación: miradas cruzadas entre Brasil y España. Granada: EUG; Porto Alegre: EDIPUCRS, 2014. p.330-355.

BRASIL. Lei no 13.634, de 20 de março de 2018. Criação da Universidade Federal de Catalão, por desmembramento da Universidade Federal de Goiás. Disponível em: http://www.planalto.gov.br/ccivil_03/_Ato2015-2018/2018/Lei/L13634.htm. Acesso em: 03 fev. 2021.

CELLARD, A. A análise documental. In: POUPART, J. et al (orgs.). A pesquisa qualitativa. Trad. Ana Cristina Nasser. Petrópolis: Vozes, 2012. p.295-316

CLANDININ, D. J.; CONNELLY, F. M. Pesquisa narrativa: experiência e história em pesquisa qualitativa. Trad. Grupo de pesquisa narrativa e educação de professores ILEEI/UFU. Uberlândia: EDUFU, 2011.

DELORY-MONBERGER, C. A história de vida: um cruzamento intercultural. In: LECHNER, E. (org.) História de vida: olhares interdisciplinares. Porto - Portugal: Edições Afrontamentos, 2009; p.17-29.

ESQUINSANI, R. S. S. As atas de reuniões enquanto fontes para a história da educação: pautando a discussão a partir de um estudo de caso. Educação Unisinos, v.11, n. 2, p.103-110, maio/ago. 2007. Disponível em: http://revistas.unisinos.br/index.php/educacao/issue/view/57. Acesso em: 23 fev. 2020. 
HONÓRIO FILHO, W; PIRES, A. P. D. O centro de informação, documentação e arquivo (CIDARQ) da UFG - Regional Catalão: narrativas e visibilidades. In: ENCONTRO DE HISTÓRIA DA EDUCAÇÃO DO CENTRO-OESTE, 5., 2019. Goiânia. Anais [...]. Goiânia: PUC Goiás, 2019. p.17-18.

LE GOFF, J. Documento/monumento. In: LE GOFF, J. História e memória. Trad. Bernardo Leitão et al. 4. ed. Campinas: Editora da UNICAMP, 1996, p.535-549.

PASSEGGI, M. C. Pierre Bourdier: da ilusão à conversão autobiográfica. FAEEB - Educação e Contemporaneidade, p.223-235, 2014. Disponível em:

https://www.revistas.uneb.br/index.php/faeeba/article/view/838. Acesso em: 23 fev. 2020

PASSEGGI, M. C.; SOUZA, E. C.; VICENTINI, P. P. Entre a vida e a formação: pesquisa (auto)biográfica, docência e profissionalização. Educação em Revista, Belo Horizonte, v.27, n.01, p.369-386, abr. 2011. Disponível em

http://www.scielo.br/scielo.php?script=sci_arttext\&pid=S010246982011000100017\&lng=en\&n rm=iso. Acesso em 23 fev. 2020.

SILVA, M. J. A história do campus Catalão UFG - 1983-2002. Goiânia: Ed. da UCG, 2009.

UFG/RC - Universidade Federal de Goiás, Regional Catalão. CIDARQ. Regimento da UFG/RC Caixa 2, s/p, 1985.

UFG/RC - Universidade Federal de Goiás, Regional Catalão. CIDARQ. Documento circular do dia 03 de maio de 1989. Caixa 2, s/p, 1989.

UFG/RC - Universidade Federal de Goiás, Regional Catalão. CIDARQ. Proposta do regimento interno, 04 de dezembro de 1992. Caixa 12, s/p, 1992a.

UFG/RC - Universidade Federal de Goiás, Regional Catalão. CIDARQ. Ata da reunião realizada no dia 02 de julho de 1992. Livro de atas do Conselho Pleno, Caixa 2, s/p, 1992b.

UFG/RC - Universidade Federal de Goiás, Regional Catalão. CIDARQ. Ata da reunião realizada no dia 27 de julho de 1994. Livro de atas do Conselho Pleno, Caixa 2, s/p, 1994a.

UFG/RC - Universidade Federal de Goiás, Regional Catalão. Ata da reunião realizada no dia 14 de setembro de 1994. Livro de atas do Conselho Pleno, Caixa 2, s/p, $1994 \mathrm{~b}$.

UFG/RC - Universidade Federal de Goiás, Regional Catalão. CIDARQ. Ata da reunião realizada no dia 20 de março de 1997. Livro de atas do Conselho Pleno, Caixa 11, s/p, 1997a.

UFG/RC - Universidade Federal de Goiás, Regional Catalão. CIDARQ. Ata da reunião realizada no dia 01 de setembro de 1997. Livro de atas do Conselho Pleno, Caixa 11, s/p, 1997b.

UFG/RC - Universidade Federal de Goiás, Regional Catalão. CIDARQ. Ata da reunião realizada no 
dia 19 de março de 1998. Livro de atas do Conselho Pleno, Caixa 11, s/p, 1998.

UFG/RC - Universidade Federal de Goiás, Regional Catalão. CIDARQ. Relatório de mandado de Vice-Diretor do Prof. Dr. Wolney Honório. Caixa 13, s/p, 2000 a.

UFG/RC - Universidade Federal de Goiás, Regional Catalão. CIDARQ. Campus de Catalão: uma universidade? Caixa 13, s/p, 2000b.

Recebido em maio 2020.

Aprovado em janeiro 2021. 